\title{
A ULTILIZAÇÃO DA INDICAÇÃO GEOGRAFICA COMO ESTRATÉGIA COMPETITIVA PARA AS EMPRESAS: UM ESTUDO DE CASO A CERCA DAS QUATRO INDICAÇÕES QUE O BRASIL POSSUI NA ATUALIDADE
}

\author{
Simone Camilo de Freitas \\ Graduada em Tecnologia em Comércio Exterior pelo Instituto Federal de Educação, \\ Ciência e Tecnologia do Rio Grande do Norte. E-mail: simonecamilo.adm@ hotmail.com \\ Elisângela Cabral de Meireles \\ Graduada em Ciências Econômicas-UFRN, esp. em Economia Regional, Comércio \\ Exterior e Globalização-UFRN, mestre em Administração (Gestão e Políticas Públicas) \\ UFRN , Professora do IFRN (Comércio Exterior e Economia) e Professora Orientadora da \\ Base de Pesquisa "Análise do Mercado Exportador do Rio Grande do Norte (IFRN). \\ E-mail- elisangela@cefetrn.br
}

\section{RESUMO}

O desafio das exportações brasileiras e a exigência por produtos de qualidade aceleraram a necessidade da obtenção de ferramentas de competitividade, neste cenário surge como resposta a Indicação Geográfica (IG). Compreender a dinâmica do comércio internacional a partir da utilização da IG como ferramenta competitiva para inserção nos mercados, caracteriza-se como sendo o principal objetivo do estudo. Seguido dos objetivos específicos que são: Identificar o cenário mundial da Indicação Geográfica; Identificar as IG's; Verificar novas proposições de Indicações Geográficas no Brasil e; Diagnosticar a conjuntura de IG's no Rio Grande do Norte. A pesquisa foi de caráter exploratória e descritiva, o universo e a amostra da pesquisa de campo foi o Ministério da Agricultura Pecuária a Abastecimento (MAPA) e o Instituto Nacional de Propriedade Intelectual (INPI), no que se refere aos meios à pesquisa foi bibliográfica e de campo. No tocante ao embasamento teórico algumas informações que se julgou interessante foram destacadas como, por exemplo, a utilização da IG como estratégia competitiva, a análise do ambiente para a formulação e implementação desse tipo de estratégia. O surgimento da IG desde os primórdios, a sua importância para o mercado nacional e internacional, e a posição da IG no Brasil na atualidade. Em resposta a problemática: De que forma a Indicação Geográfica pode impactar sobre a dinâmica do comércio internacional praticado pelo Brasil. Ela impacta na medida em que o país inserido num mundo globalizado, a competição entre os países a fim de buscar posições favoráveis as suas vendas está cada vez maior. Onde os consumidores cada vez mais exigentes, buscam sempre produtos de qualidade e de procedência, fazendo com que a IG torne-se uma importante ferramenta de competitividade. Contudo o produto com o registro de IG pode não ser melhor do que outros, mas é diferenciado, seja por seus aspectos, ou seu modo de fabricação, destacandose e ganhando força para enfrentar a competitividade exigida pelo mercado.

PALAVRAS-CHAVE: Indicação Geográfica, Comércio internacional, Estratégia competitiva. 


\title{
THE USE OF GEOGRAPHICAL INDICATION (IG) AS A COMPETITIVE STRATEGY FOR COMPANIES: A CASE STUDY ABOUT THE FOUR GEOGRAPHICAL INDICATIONS THAT HAVE IN BRAZIL CURRENT
}

\begin{abstract}
ABSTRAT
The challenge of Brazilian exports and demand for quality products, accelerated the need to obtain tools for competitiveness in this scenario comes as a response to Geographical Indication (GI). Understanding the dynamics of international trade from the use of GIs as a tool for integration in competitive markets, characterized as being the main objective of the study. Followed by specific objectives are: To identify the scene of the Geographical Indication; Identify the IG's; Check new propositions of Geographical Indications in Brazil and, overall diagnosis of GI's in Rio Grande do Norte. The research was exploratory and descriptive in nature, the universe and the sample of field research was the Ministry of Agriculture Livestock Supply (MAPA) and National Institute of Intellectual Property (INPI), regarding the means to search for literature and was field. Concerning the theoretical held some interesting information that have been highlighted, such as the use of GIs as a competitive strategy, analysis of the environment for the formulation and implementation of such strategy. The emergence of the IG from the start, its importance in national and international market, and the position of IG in Brazil nowadays. In response to question: How did the Geographical Indication can impact on the dynamics of international trade practiced by Brazil. It impacts in that country in a globalized world, the competition between countries to seek favorable positions its sales are growing. Where consumers increasingly demanding, always seek products of quality and origin, making the GA becomes a major tool of competitiveness. However the product with the registration of GIs can not be better than others, but it is different, whether by its aspects, or its method of manufacture, particularly and gaining strength to face the competitiveness required by the market.
\end{abstract}

KEY WORDS: Geographical Indication. International trade. Competitive strategy. 


\section{A ULTILIZAÇÃO DA INDICAÇÃO GEOGRAFICA COMO ESTRATÉGIA COMPETITIVA PARA AS EMPRESAS: UM ESTUDO DE CASO A CERCA DAS QUATRO INDICAÇÕES QUE O BRASIL POSSUI NA ATUALIDADE}

\section{INTRODUÇÃO}

Para Maluf (2000), o comércio exterior assume cada vez mais papel vital para a maioria dos países, e constitui-se numa variável fundamental para o desenvolvimento das nações. Segundo Kakuta et al (2006) o desafio das exportações brasileiras e a crescente exigência dos consumidores por produtos de qualidade aceleraram a necessidade, por parte dos produtores, da obtenção de ferramentas inovadoras de competitividade que possam manter e ampliar mercados.

De acordo com o (BRASIL, 2007) pode-se conceituar Indicação Geográfica como sendo a indicação de um produto ou serviço como originário de um local, região ou país, quando determinada reputação, característica e/ou qualidade possam ser vinculadas essencialmente a esta sua origem particular.

Neste contexto compreender a dinâmica do comércio internacional a partir da utilização da Indicação Geográfica como ferramenta competitiva para inserção nos mercados, caracteriza-se como sendo o principal objetivo do presente estudo, seguido dos objetivos específicos que são:

- Identificar o cenário mundial da Indicação Geográfica;

- Identificar as Indicações Geográficas brasileiras;

- Verificar novas proposições de Indicações Geográficas no Brasil e;

- Diagnosticar a conjuntura de Indicações Geográficas no Rio Grande do Norte.

Diante do exposto e tomando por base a participação do Brasil no comércio estrangeiro, pode-se fazer a seguinte indagação: De que forma a Indicação Geográfica, pode impactar sobre a dinâmica do Comércio Internacional praticado pelo Brasil?

A justificativa para o estudo alicerça-se em alguns aspectos relevantes para a minha vida pessoal, profissional e acadêmica. A pessoal, diz respeito ao interesse em realizar uma pesquisa sobre um assunto inovador e que não foi tratado em nenhuma pesquisa monográfica do curso de Comércio Exterior do Instituto Federal de Educação Ciência e Tecnologia do Rio Grande do Norte (IFRN) até o momento. Na profissional, refere-se à possibilidade de acesso de uma gama de conhecimentos práticos que posteriormente poderão ajudar na minha vida profissional. A terceira relevância do estudo, que é a acadêmica, reside no fato de aprofundar os conhecimentos sobre questões relacionadas às vantagens e as estratégias competitivas entre as empresas e suas táticas para manterem-se bem posicionadas no comércio internacional. Bem como contribuir com o curso na obtenção de uma nova fonte de pesquisa bibliográfica sobre assuntos que o permeiam.

Além das relevâncias mostradas anteriormente, o estudo também contribui para a conjuntura sócio-economica e para a política pública de comércio exterior praticado pelo Brasil. Na área sócio-economica, o estudo colabora para a soma de conhecimentos sobre o 
tema, pois se trata de um assunto inovador no tocante às questões referentes a Criações Intelectuais. E no aspecto da política pública de comércio exterior, Pedreira (2007), afirmou que as Indicações Geográficas (IG's) podem desempenhar um papel muito importante na repartição das benesses do crescimento econômico, contribuindo para a divisão de renda e o crescimento regional, em especial nos países mais pobres ou em desenvolvimento.

Segundo o tecnologista em propriedade industrial, Pedreira (2007) um fator limitante das IG's é que elas podem tornar-se um problema, em especial no âmbito das negociações externas, quando existe uma marca já registrada idêntica ou semelhante a uma Indicação Geográfica estrangeira, impedindo o uso desta indicação. Diante do cenário exposto, a Indicação Geográfica é na atualidade uma ferramenta de suma importância para empresas, pois devido ao crescimento e evolução dos mercados, e em meio o crescimento e surgimento de novas empresas, somente as mais fortes e bem preparadas é que conseguirão se manter na turbulência, que se tornou hoje o mercado nacional e internacional.

\section{A DINÂMICA DO COMÉRCIO INTERNACIONAL E A INDICAÇÃO GEOGRÁFICA: Globalização e a Indicação Geográfica como ferramenta de estratégia competitiva}

Segundo Ratti (2000) para muitos o comércio internacional, nada mais seria do que um prolongamento do comércio interno, podendo ser analisado mediante aplicação dos mesmos modelos e critérios utilizados para o comércio interno. O principal motivo é a impossibilidade de uma região ou país produzir vantajosamente todos os serviços e bens que necessitam os habitantes de tal lugar.

Segundo o (INSTITUTO NACIONAL DE PROPRIEDADE INDUSTRIAL, 2009), a Lei de Propriedade Industrial, Lei Nacional $n^{\circ}$ 9.279, de 14 de maio de 1996, não se define o significado de Indicação Geográfica, mas estabelece suas espécies, que são a Indicação de Procedência e a Denominação de Origem. Onde a Indicação de Procedência é caracterizada pelo nome geográfico que se torna conhecido pela produção, extração ou fabricação de algum produto, ou pela produção de determinado serviço. De forma que possibilite a agregação de valor ao produto, ou serviço, quando indicado a sua origem, independente de quaisquer outras características. Já a Denominação de Origem refere-se ao nome geográfico que designe um produto ou serviço cujas qualidades ou características se devam exclusivamente ao meio geográfico que está inserido, onde está incluído tanto fatores naturais quanto humanos.

No que se refere ao conceito do que venha a ser estratégia, é a partir da visão de alguns autores que se tenta alcançar uma definição. Segundo Cavalcante (2007) a palavra estratégia nasceu do uso militar vista como uma grande tática ela era centrada na força, onde o comando decidia todos os passos que deveriam ser seguidos nas frentes de batalha.

No século XX, de acordo com Cavalcante (2007) outras definições apareceram com menos enfoque na força e passando a ser a seleção de meios e objetivos que privilegiavam os fatores psicológicos dos envolvidos. 


\section{Análise do ambiente onde a estratégia da Indicação Geográfica será executada}

Para que se consiga o êxito de uma estratégia é necessária uma complexa análise do ambiente onde a empresa está ou pretenderá inserir-se, para Certo e Peter (1993), a análise dos fatores internos e externos de uma organização é uma ferramenta bastante útil para compreender a situação global em que a empresa está inserida. Esta abordagem, denominada de análise SWOT (strenghs, weaknesses, oportunities e threats) tenta o equilíbrio entre os pontos fortes e fracos internos da organização com as oportunidades e ameaças do ambiente externo a empresa.

As estratégias com que as empresas utilizam para se manterem no mercado na maioria das vezes estão baseadas nas forças competitivas do Michael Porter. Que são: a rivalidade entre os concorrentes existentes, produtos substitutos, poder de barganha dos consumidores, novos entrantes e fornecedores, para o presente estudo serão detalhados as quatro primeiras forças.

\section{Surgimento da Indicação Geográfica, formulação e implementação de estratégias competitivas}

Para Kakuta et al (2006) desde os primórdios da era romana os produtos são rotulados e distinguidos em relação ao local de produção. Segundo Soeiro (2005) alguns historiadores dizem que esta situação já era habitual entre os povos que moravam próximos ao Mar Mediterrâneo, sendo as primeiras Denominações de Origem ou Denominações Geográficas da Humanidade.

Segundo o autor acima a França tem importância histórica no que se refere às IG's, o selo oficial sobre qualidade dos alimentos mais antigo desse país é a Apelação de Origem Controlada (AOC). Para Soeiro (2005) Portugal foi o primeiro país da Europa a estabelecer legalmente o sistema de proteção da denominação de origem, reportando se ao Vinho do Porto, no ano de 1756. Devido a uma crise no setor vinícola, em 1905 surgiu uma Lei sobre Falsificações e Fraudes em Matéria de Produtos. Devido ao fracasso das duas leis, a Apelação de Origem Controlada foi instaurada e regulamentada em 1935, quando foram criados o Instituto Nacional de Apelações de Origem (INAO) e o Comitê Nacional para vinhos e aguardentes. Conseqüentemente com o sucesso, as Apelações de Origens Controladas foram estendidas a todos os produtos alimentares por intermédio da lei de 1990.

\section{Indicação Geográfica e vantagem competitiva}

Para Kakuta et al (2006), as IG's por ser um direito de propriedade intelectual, da mesma forma que as marcas e patentes, possuem prerrogativa expressa e reconhecida pelo tratado de comércio sobre direitos de propriedade intelectual da Organização Mundial do Comércio (OMC), conhecido como Trade-Related Aspects of Intelectual Property Rights (TRIPS). De acordo com autor citado, cada país é responsável pelo estabelecimento do 
regramento legal e pela proteção das Indicações Geográficas de tal lugar, pois elas são consideradas um patrimônio nacional.

Segundo Soeiro (2005), nos dias atuais muitos consumidores estão à procura de produtos com uma qualidade caracterizada por fatores naturais, onde estão dispostos a pagar por sua efetiva certificação de qualidade ligada a sua origem e a um "saber fazer" naturalmente e historicamente conhecidos.

\section{A Indicação Geográfica no Brasil}

Segundo o MAPA (2007), no Brasil os exemplos notórios de Indicação Geográfica são: o Vale dos Vinhedos (vinhos e espumantes), Região do Serrado Mineiro (café), Pampa Gaúcho (carne) e Paraty (cachaça). De acordo com a Associação dos Produtores de Vinhos Finos do Vale dos Vinhedos (2007) a região do Vale dos Vinhedos, situado na Serra Gaúcha, é a primeira região vinícola do Brasil a obter Indicação de Procedência de seus produtos em 2001.

Em relação a novas proposições de IG's percebe-se que no segmento de produtos amazônicos a IG pode ser muito importante na sua valorização. De acordo com o Tecnologista em Propriedade Intelectual do INPI, Pedreira apud Morais (2009), até o momento não há, junto ao instituto, qualquer pedido para registro de IG dos produtos da região norte. Na opinião do pesquisador Tonieto (2009 da Empresa Brasileira de Pesquisa Agropecuária (Embrapa) Uva e Vinhos, apud MORAIS, 2009) a principal característica dos produtos amazônicos é a originalidade.

No Estado do Rio Grande do Norte, os produtos que podem obter a Indicação Geográfica são o queijo de coalho e de manteiga do Sérido e o melão de Mossoró, no caso do queijo, um projeto está sendo coordenado pelo Sebrae que possui em uma das diretrizes estratégicas ampliar o acesso dos pequenos produtores ao mercado. Segundo o site Correio da tarde os produtores de melão da região de Mossoró no estado do Rio Grande do Norte estão buscando o selo de Indicação Geográfica, na modalidade Indicação de Procedência. Para que isso ocorra, o Sebrae do estado esta desde o ano passado trabalhando nesse projeto e este ano está ampliando as parcerias.

\section{METODOLOGIA}

A metodologia utilizada caracterizou-se por uma pesquisa de natureza exploratóriodescritiva. De acordo com Gil (2002), as pesquisas exploratórias possuem como principal objetivo o aprimoramento de idéias ou a descoberta de intuições. Neste sentido a pesquisa foi de caráter exploratória porque para a formulação da problemática fez necessária a busca por informações a respeito do assunto. E descritiva porque no decorrer do projeto foi necessário descrever fatos, fenômenos e analisá-los.

O universo da pesquisa de campo foram as Instituições que tratam do assunto, o Ministério da Agricultura Pecuária a Abastecimento (MAPA) e o Instituto Nacional de 
Propriedade Intelectual (INPI), órgãos públicos do Governo Federal. A amostra a foi definida pelo critério de acessibilidade, onde os representantes destes órgãos foram questionados.

Para a coleta das informações bibliográficas, utilizou-se de dados secundários obtidos em artigos na internet, e em revistas e jornais. Já para a pesquisa de campo, os dados primários foram obtidos através da elaboração de questionários enviados ao MAPA e ao INPI, órgãos públicos que trabalham com questões ligadas a IG.

\title{
PERCEPÇÃO DOS GESTORES INSTITUCIONAIS ACERCA DA DINÂMICA DA INDICAÇÃO GEOGRÁFICA NO BRASIL E NO RIO GRANDE DO NORTE
}

\author{
O Ministério da Agricultura, Pecuária e Abastecimento (MAPA) e o Instituto \\ Nacional de Propriedade Intelectual (INPI) e a Indicação Geográfica como \\ ferramenta competitiva
}

Segundo a zootecnista do Ministério da Agricultura Pecuária e Abastecimento (MAPA) ao promover e incentivar ações de IG's de produtos agropecuários, este instituto se estabelece como um instrumento institucional de desenvolvimento sustentável e proteção à propriedade intelectual. Agregando assim valor material e imaterial a produtos agropecuários de qualidade e renome, ressaltando as identidades culturais, a organização da produção e a inocuidade e qualidade dos mesmos.

Já em relação ao Instituto Nacional de Propriedade Intelectual (INPI) o respondente falou que o objetivo principal desta instituição é viabilizar a constituição de um sistema sustentável de Indicações Geográficas para vários produtos e serviços existentes no Brasil, de forma a consolidar o comando legal do INPI com o dever de criar condições para a proteção das IG's no Brasil.

Segundo a respondente do MAPA quando perguntada porque a Indicação Geográfica é considerada uma ferramenta de competitividade tanto no mercado interno quanto no externo, ela falou que a presença de um selo de IG mostra que se trata de um produto genuíno cuja especificidade se deve a sua origem.

Para o tecnologista do INPI a IG se tornará um instrumento de competitividade, à medida que serve para diferenciar um produto com o registro de IG dos similares. E também por servir como uma ferramenta de reorganização da cadeia produtiva no local de origem do produto, onde os produtores terão um meio concreto de proteção de seus interesses, através dos mecanismos legais de combate ao uso irregular do registro. 


\section{Fatores de interveniência (favoráveis e limitantes) para a adoção de uma IG}

Na opinião da fiscal agropecuária do Ministério da Agricultura Pecuária e Abastecimento alguns fatores de interveniência como o apoio do governo, fatores relativos ao produto e ao seu meio de produção são caracterizados como pontos favoráveis a adoção das Indicações Geográficas. Em relação ao produto em si, ela revela que é imprescindível que possíveis IG's apresentem, no mínimo, as peculiaridades intrínsecas previstas pela legislação de propriedade intelectual de renome e relação com o ambiente, para que iniciem a busca pelo selo.

$\mathrm{Na}$ opinião do tecnologista do Instituto Nacional de Propriedade Intelectual assim como a respondente do MAPA o apoio do governo, fatores relativos ao produto e ao seu meio de produção, além de outros como, por exemplo, reputação estabelecida, formação cultural e articulação dos agentes econômicos locais podem ser destacados como fatores favoráveis para a adoção da IG.

De acordo com a respondente do Ministério da Agricultura Pecuária e Abastecimento sua visão dos papeis dos governos (Federal e Estadual) no incentivo de implementação de IG, é que as diversas esferas de governo são imprescindíveis à execução dos trabalhos institucionais de alcance social. Já o respondente do Instituto Nacional de Propriedade Intelectual os governos (Federal e Estadual) no incentivo de implementação de IG, deve observar as seguintes linhas básicas. Identificação de possíveis produtos a receber uma IG; Orientação aos estes potenciais detentores do registro; Subsídio técnico para o nivelamento e melhoria da cadeia produtiva; Apoio à preparação dos documentos burocráticos necessários ao registro.

Para o tecnologista do Instituto Nacional de Propriedade Intelectual da mesma forma que o apoio do governo é um fator favorável, a falta torna-se um ponto desfavorável, para a adoção da IG, pois a falta de apoio se concretiza devido às dificuldades de financiamento. Na opinião do respondente do INPI a falta de conhecimento sobre o tema das IG's pode ser classificado também como um fator de interveniência limitante para a adoção de uma Indicação Geográfica. A respondente do Ministério da Agricultura Pecuária e Abastecimento também considera a falta de apoio em alguns setores específicos e de conhecimento como sendo fatores de interveniência limitantes, ou seja, desfavorável à implantação de uma Indicação Geográfica.

\section{A situação da Indicação Geográfica no Brasil na percepção dos gestores}

No tocante aos benefícios diretos e indiretos que uma região adquire ao possuir produtos com o registro de IG, a fiscal agropecuária do Ministério da Agricultura Pecuária e Abastecimento falou que regiões protegidas por Indicações Geográficas tendem a oferecer benefícios no desenvolvimento econômico-social da área geográfica. No mercado ela falou que a instituição de Indicações Geográficas resulta em aumento do valor econômico dos produtos, além do que torna mais estável a demanda dos mesmos, concentrando a oferta e acessando mercados de nicho. 
O respondente do Instituto Nacional de Propriedade Intelectual disse que no país existem inúmeros outros produtos/serviços com potencial para receber o selo, entre eles os citados acima pela fiscal agropecuária do Ministério da Agricultura Pecuária e Abastecimento. Citou alguns produtos/serviços que têm potencial para ganhar o registro. O queijo de coalho do agreste pernambucano, e a carne de sol; O Seridó da Paraíba ganha reputação com o algodão colorido. O Amazonas possui os peixes decorativos de Barcelos, o artesanato dos povos indígenas e outros produtos, como o açaí, palmito de pupunha e o cacau, entre outros.

Já a respondente do Ministério da Agricultura Pecuária e Abastecimento mostrou que o instituto vem realizando um diagnóstico nacional de potenciais IG's nas cinco regiões, visando o levantamento de informações que gerem subsídios aos técnicos que atuam na área para implementação e proteção dessas IG's. Esse estudo levantou cento e onze potenciais IG's, envolvendo os seguintes grupos de produtos: amêndoas e nozes, artesanatos, bebidas, carnes, doces, especiarias, farinhas e féculas, fitoterápicos, flores, frutas, grãos, laticínios, mel, peixes, perfumes e produtos da sociobiodiversidade.

Em relação ao Rio Grande do Norte a fiscal agropecuária do Ministério da Agricultura Pecuária e Abastecimento disse que atualmente no Estado, há dois processos de criação de IG: os queijos de coalho e de manteiga do Seridó e o melão do Vale Açu-Mossoró, além do estudo diagnóstico de vários outros produtos/ regiões potenciais IG's, como Serra do Mel, Brejinho, além de outros produtos do Seridó.

\section{A diferença entre Indicação Geográfica e patente, ambos classificados como sendo direitos de propriedade intelectual}

De acordo com o respondente do Instituto Nacional de Propriedade Intelectual, a diferença entre uma IG e uma patente é o fato de que a IG é um ativo coletivo, de natureza declaratória, não sendo criado e sim que ocorre quase que naturalmente como resultado de fatores tanto naturais, quanto humanos. Já a patente, não é algo que ocorre de forma natural ela é uma invenção que atende aos requisitos de novidade, atividade inventiva e aplicação industrial.

Segundo o respondente do Instituto Nacional de Propriedade Intelectual em relação à questão da Indicação Geográfica Protegida, este falou que no Brasil não existe tal previsão. Já a fiscal do Ministério da Agricultura Pecuária e Abastecimento de acordo com a atual legislação, as Indicações Geográficas são classificadas nas modalidades de: Indicação de Procedência ou Denominação de Origem. Segundo o respondente quando perguntado sobre sua opinião no que tange à questão da IG tornar-se um problema quando existe uma Indicação Geográfica estrangeira impedindo seu uso. Aquele respondeu que o acordo TRIPS na esfera da OMC estabelece que as Indicações Geográficas homônimas poderão coexistir se revestidas de distinção suficiente para não induzir o consumidor ao erro. $\mathrm{Na}$ opinião do respondente quando perguntado se este modelo concentra o poder estatal e provoca confusão junto aos consumidores com o ato de somente indicar a origem do produto sem que lhe seja atribuído o valor de propriedade intelectual. 


\section{CONSIDERAÇÕES FINAIS}

A partir da análise realizada no decorrer desta pesquisa pode-se dá por alcançados o objetivo tanto geral quanto os específicos e a problemática posta na introdução. Onde no que se refere ao objetivo geral que é compreender a dinâmica do comércio internacional a partir da utilização da Indicação Geográfica como ferramenta competitiva para a inserção nos mercados.

De acordo com o que foi visto a Indicação Geográfica torna-se uma ferramenta de competitividade na medida em que este registro identifica a originalidade e a qualidade do produto frente aos seus concorrentes. Em relação aos objetivos específicos, um deles é analisar o cenário mundial da Indicação Geográfica, neste ponto pode-se observar que as IG's apesar de serem um assunto pouco conhecido no âmbito das criações intelectuais desde a era romana quando se refere ao surgimento da Indicação Geográfica.

Outro objetivo era analisar o cenário atual de IG no Brasil, observa-se que este se encontraem fase de crescimento, haja vista que apenas quatro produtos possuem este tipo de registro. Como mostrado na análise dos dados, um estudo realizado pelo Ministério da Agricultura e o respondente do Instituto Nacional de Propriedade Intelectual revelou um grupo de produtos com potencial a receber o selo de Indicação Geográfica.

Em relação ao Rio Grande do Norte em especial, atualmente há dois processos de IG, um para o queijo de manteiga e coalho da Região do Seridó e outro para o melão de Mossoró, na análise dos dados é mostrado que outros produtos/regiões podem ser beneficiados com o selo de Indicação Geográfica

Em resposta a problemática exposta na pesquisa, onde se faz a seguinte indagação, de que forma a Indicação Geográfica pode impactar sobre a dinâmica do comércio internacional praticado pelo Brasil. Pode-se dizer que a IG impacta no comércio exterior praticado pelo país na medida em que este se vê inserido em um mundo globalizado, onde a competição entre os países a fim de buscar posições favoráveis a venda de seus produtos está cada vez maior. E devido a essa concorrência os consumidores estão cada vez mais exigentes em relação ao que compram, buscando sempre produtos de qualidade e de boa procedência.

\section{REFERÊNCIAS BIBLIOGRÁFICAS}

1. AGENCIA SEBRAE DE NOTICIAS. Rede de Tecnologia Social. Empresários debatem certificação de indicação geográfica. Disponível em: $<$ http://www.rts.org.br/noticias/destaque-1/empresarios-debatem-certificacao-deindicacao-geografica>. Acesso em: 14. nov. 2008.

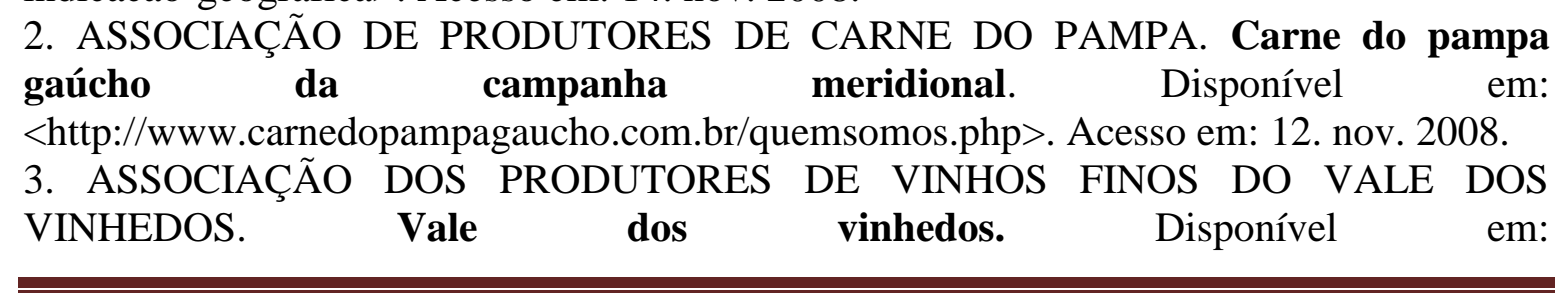


<http://www.sitedovinhobrasileiro.com.br/folha.php?pag=mostraregiao.php\&num=VAL > Acesso em: 10. nov. 2008.

4. CAVALCANTE, Marly (Org.) Gestão estratégica de negócios: evolução, cenários, diagnóstico e ação. 2. ed. rev. e ampl. São Paulo: Thomson Learning, 2007.

5. CERTO, Samuel C; Perter, J. Paul. Administração estratégica: planejamento e implantação da estratégia. Makron Books: São Paulo, 1993.

6. CORREIO DA TARDE. RN busca indicação geográfica do melão. Disponível em: $<\mathrm{http}: / /$ www.correiodatarde.com.br/editorias/economia-41400>. Acesso em: 22. nov. 2009.

7. CHIAVENATO. Idalberto. Introdução à teoria geral da administração: uma visão abrangente da moderna administração das organizações. 3 ed. rev. e atualizada. Rio de Janeiro: Elsevier, 2004.

8. GAZETA DAS CIDADES. Paraty News: cachaça ganha Indicação geográfica. Disponível em: <http://gazetadascidades.com.br/pages/arquivos/materias/paraty017.htm>. Acesso em: 18. nov. 2008.

9. GIL, Antônio Carlos. Como elaborar projetos de pesquisa. 4 ed. São Paulo: Atlas, 2002.

10. HARTURG, Douglas S. Negócios internacionais. Rio de Janeiro: Qualitymark, 2002.

11. INSTITUTO NACIONAL DE PROPRIEDADE INDUSTRIAL. Indicação geográfica. Disponível em: <http://www.inpi.gov.br>. Acesso em: 20. out. 2008.

12. INSTITUTO NACIONAL DE PROPRIEDADE INDUSTRIAL. 160 anos de lucros com a indicação geográfica. Disponível em: <http://www.inpi.gov.br/noticias/160-anosde-lucros-com-a-indicacao-geografica>. Acesso em: 02. jun. 2009.

13. INSTITUT NATIONAL DE LA PROPRIÉTÊ INDUSTRIELLE. L'INAO et I'INPI signent une convention relative à la protection des Indications géographiques. Disponivel em: <http://www.inpi.fr/fr/presse/espace-presse/communiques-de-presse/detailcommunique/article/linao-et-linpi-signent-une-convention-relative-a-la-protection-desindications-geographiques.html?tx_ttnews\%5BbackPid\%5D=1984\&cHash=06c6243c47>. Acesso em: 25. maio. 2009

14. KAKUTA, Susana Maria. SOUZA, Alessandra Lo Loureiro de; SCHWANKE, Fernando Henrique e GIESBRECTH, Hulda Oliveira. Indicações geográficas: guia de respostas. Porto Alegre: SEBRAE/RS, 2006.

15. KAPLAN, Robert, S. e NORTON, David P. A estratégia em ação: balanced scorecard. Tradução Luiz Euclides Trindade Frazão Filho. Rio de Janeiro: Elsevier, 1997.

16. KAPLAN, Robert S. Organização orientada para a estratégia: como as empresas que adotam o balanced scorecard prosperam no novo ambiente de negócios. Rio de Janeiro, Elsevier, 2000.

17. LUCENA Raidon; NETO, Moraes. Agência Sebrae de noticias. Região Seridó (RN) busca indicação geográfica do queijo regional. produtores de queijo norteriograndenses buscam também fortalecimento da marca, tomando como base aspectos tradicionais e culturais da região. 2009. Disponível em: $<$ http://www.agenciasebrae.com.br/noticia.kmf?noticia=8247217\&canal=199\&total=2984 \&indice=0 $>$. Acesso em: 27. mar. 2009.

18. MALUF, Sâmia Nagib. Administrando o comércio exterior do Brasil. São Paulo: Aduaneiras, 2000.

BRASIL. Ministério da Agricultura, Pecuária e Abastecimento. Indicação Geográfica (IG). Disponível em: <http://www.agricultura.gov.br>. Acesso em: 13. out. 2008.

19. MARTINS, Gilberto de Andrade. Manual para a elaboração de monografias e dissertações. 3 ed. São Paulo: Atlas, 2002. 
20. MINTZBERG, Henry; AHLSTRAND, Bruce e LAMPEL, Joseph. Safári de estratégia: um roteiro pela selva do planejamento estratégico. Porto Alegre: Bookman, 2000.

21. MORAIS, Maria Lúcia. Noticias da Amazônia, destaque da Amazônia. Registro de Indicação Geográfica pode qualificar e ampliar o mercado de produtos amazônicos. Disponível em: <http://www.noticiasdaamazonia.com.br/6820-registro-de-indicacaogeografica-pode-qualificar-e-ampliar-o-mercado-de-produtos-amazonicos/>. Acesso em: 07. mar. 2009.

22. PEDREIRA, Raul Bittencourt. 2007. SIMPÓSIO INTERNACIONAL DE INDICAÇÕES GEOGRÁFICAS, 1., 2007, Beijing.. Anais Eletrônicos ... Beijing. Disponível em: <http://raulbittencourt.multiply.com/journal/item/70>. Acesso em: 28. nov. 2008.

23. PORTER, Michael. Vantagem competitiva: criando e sustentando um desempenho superior. Rio de Janeiro: Elsevier, 1989.

24. RATTI, Bruno. Comércio internacional e câmbio. 10. ed. São Paulo: Aduaneiras, 2000.

25. REGIÃO Seridó (RN) busca indicação geográfica do queijo regional. produtores de queijo norte-riograndenses buscam também fortalecimento da marca. 2009. Disponível em: <http://www.clicrbs.com.br/canalrural/jsp/default,jsp?uf=1\&local=1\&action=noticias\&id= 2443546\&section=noticias $>$. Acesso em: 27. mar. 2009.

26. SOEIRO, Ana. Denominações de origem e indicações geográficas protegidas: a sua importância. $2005 . \quad$ Disponível em: <http://www.pluridoc.com/Site/FrontOffice/default.aspx?Module=Files/FileDescription\&I $\mathrm{D}=1910 \&$ lang=pt $>$. Acesso em: 28. maio 2009.

27. TAVARES, Mauro Calixta. Gestão estratégica. 2. ed. São Paulo: Atlas, 2005.

28. VAZQUEZ, José Lopes. Comércio exterior brasileiro. 5. ed. São Paulo: Atlas, 2001.

29. WASHINGTON. Produtores discutem o futuro do queijo. Diário de Natal do Seridó Disponível em: <http://pesquisa.dnonline.com.br/document/?view=23375>. Acesso em: 03. nov. 2008.

30. WRIGHT, Peter L.; KROLL, Mark J. e PARNEEL, John. Administração estratégica: conceitos. São Paulo: Atlas, 2000. 